\title{
Karyokinesis and Septum Formation during the Regeneration of Incomplete Cell Walls in Protoplasts of Schizosaccharomyces japonicus var. versatilis: a Time-lapse Microcinematographic Study
}

\author{
By MIROSLAV GABRIEL \\ Department of Biology, Faculty of Medicine, J. E. Purkyně University, 66243 Brno, \\ Czechoslovakia
}

(Received 22 July 1983; revised 2 November 1983)

\begin{abstract}
Regeneration in flattened Schizosaccharomyces japonicus var. versatilis protoplasts was studied with regard to nuclear behaviour, septum formation and lateral wall regeneration. In the course of protoplast regeneration all stages of the cell cycle were realized. However, the time sequence was conserved only between nuclear division and the beginning of septum formation. From this it is suggested that the signal initiating septum formation was issued by the dividing nucleus. Its primary target was not the original cell wall. However, the wall, though incomplete, was an essential prerequisite for the signal to be put into operation, i.e. for septation to begin. Incomplete cell wall regeneration allowed cytokinesis but not reversion of protoplasts into cells with their genetically determined cylindrical cell shape.
\end{abstract}

\section{INTRODUCTION}

Interrelations of essential processes of the cell cycle have been studied in regenerating yeast protoplasts, in which karyokinesis takes place (Nečas et al., 1961; Nečas, 1959; Havelková \& Kř́palová, 1980), but cytokinesis occurs only after cell walls have been regenerated (Nečas, 1971 ; Havelková, 1981; Nečas \& Svoboda, 1981). However, the experimental study of the association of karyokinesis with septation is hindered by the fact that it is very difficult to detect nuclei in vivo. Nuclei are clearly visible in intact yeasts growing in $18-20 \%(\mathrm{w} / \mathrm{v})$ gelatine nutrient medium (Müller, 1956; Robinow, 1975). However, nuclei become progressively less visible with increasing gelatin concentration. In Saccharomyces cerevisiae protoplasts regenerating in $30 \%$ gelatin (or $2 \%, w / v$, agar) nuclei are practically invisible (Nečas, 1961 ; Svoboda, 1966; Gabriel, 1971). Nuclei can be visualized in flattened $S$. cerevisiae protoplasts grown on the surface of solid media (Nečas et al., 1961), but these protoplasts never regenerate their complete cell walls nor divide nor revert to cells.

In Schizosaccharomyces japonicus var. versatilis, nuclei are distinctly visible under the phasecontrast microscope (Kopecká, 1975; Kopecká \& Gabriel, 1978) despite the absence of gelatin. Therefore the relation between nuclear cycle events and cytokinesis was studied in the protoplasts of this yeast. Preliminary results of this work have been presented elsewhere (Gabriel, 1984).

\section{METHODS}

Strain. The yeast used in this study was Schizosaccharomyces japonicus var. versatilis CC-60-255 (sometimes referred to as Schizosaccharomyces versatilis), kindly provided by Professor H. J. Phaff of the University of California, Davis, USA. It was grown on $2 \%(\mathrm{w} / \mathrm{v})$ malt extract agar, $\mathrm{pH} 5 \cdot 5$. Stock cultures were stored at $4{ }^{\circ} \mathrm{C}$.

Protoplast preparation and cultivation. Protoplasts were prepared by means of digestive enzymes of Helix pomatia (Gabriel \& Kopecká, 1983). The washed protoplasts were transferred to mannitol/stabilized malt extract medium. For microcinematographic observation, a small droplet of the protoplast suspension (approximately $10^{4}$ protoplasts) was put on a cover slip coated with a thin layer of malt extract agar. The cover slip was carefully placed on a 

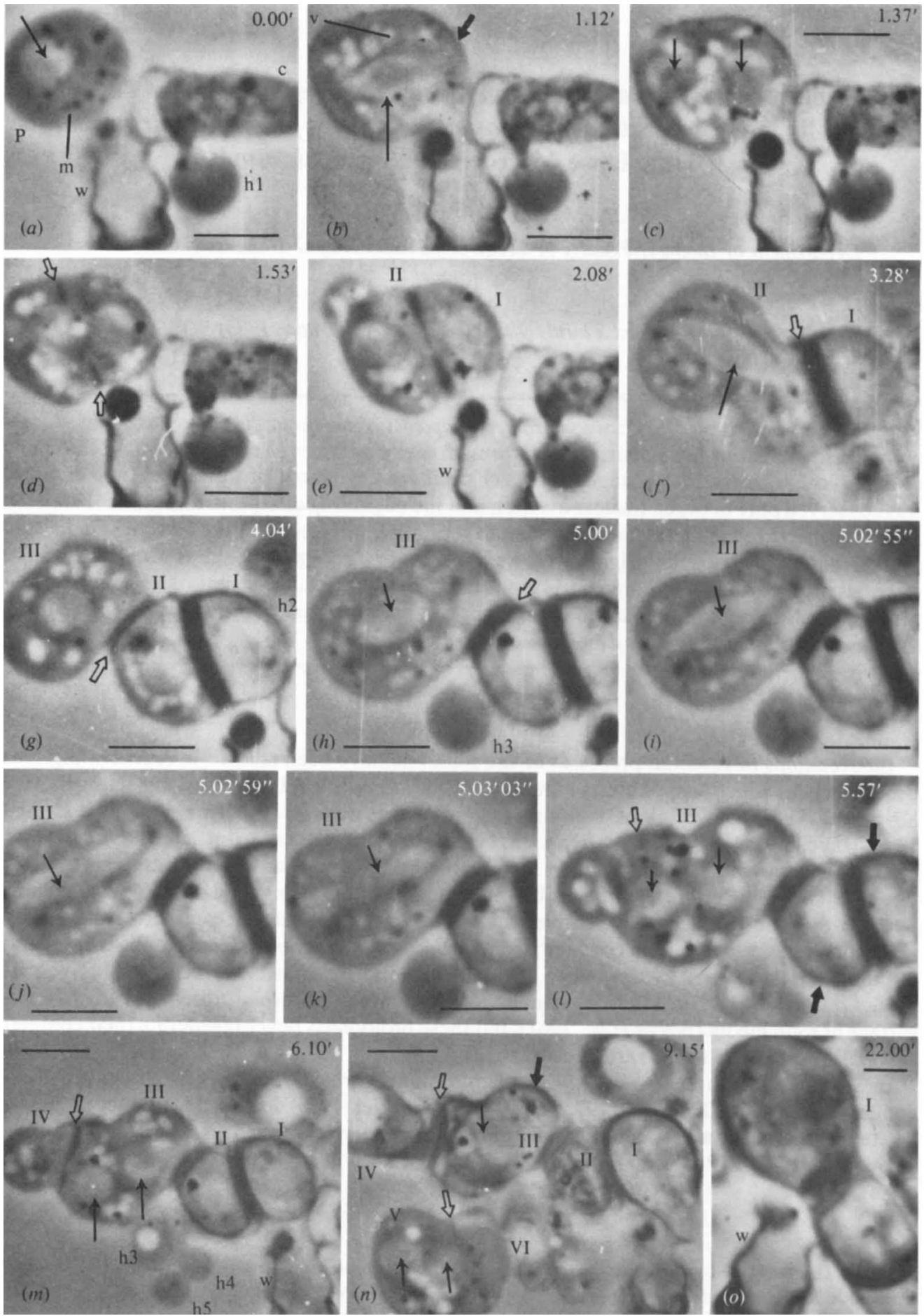

Fig. 1. Time-lapse microcinematography of growth and cell wall regeneration in flattened protoplasts of $S$. japonicus var. versatilis. Nuclei are indicated by simple arrows, septa by unfilled arrows, and regenerating wall by bold arrows. Phase-contrast microscopy. The bar markers represent $5 \mu \mathrm{m}$ in $(a)$ to 
slide such that the agar layer became sandwiched in between. Capillary forces together with the weight of the slip resulted in partial flattening of the protoplasts in which all cellular structures were situated in the focal plane.

Microcinematography. This was done with a $16 \mathrm{~mm}$ recording camera (RfS Meopta, Czechoslovakia) equipped with a time-recorder (Regisstimer B4, Meopta, Brno, Czechoslovakia), attached to a modified light microscope (Amplival, Carl Zeiss, Jena, GDR). Phase-contrast photomicrographs were taken with the same microscope through a yellow-green filter at a primary magnification of $\times 250$. The frequency of recording was about 1 picture every $4 \mathrm{~s}$; exposure was $0.5 \mathrm{~s}$ on $16 \mathrm{~mm}$ inverse black and white film (Fomapan $21 \mathrm{DIN}$ ).

\section{RESULTS}

A total of 33 preparations were studied by time-lapse microcinematography and 21 specimens by serial microphotography. Probably due to differences in the degree of flattening, the timing of cell cycle steps (growth rate, onset of karyokinesis, rate of formation of wall structures, etc.) varied markedly with each protoplast preparation.

Karyokinesis. Karyokinesis took about $3 \mathrm{~min}$ in the protoplasts. A spherical nucleus (Fig. $1: a$; $g$, III) became oval in shape (Fig. $1: h$, III), then took a spindle-like shape (Fig. $1: b ; i$, III), formed a ribbon-like structure (Fig. $1: j$, III), and divided rapidly into two daughter nuclei (Fig. $1: c ; k$, III $; l$, III) which remained connected by a thin bridge for a few tens of seconds. In resting

$(n)$; the bar marker in $(o)$ represents $2.5 \mu \mathrm{m}$. All the times shown are counted from the start of the incubation.

(a) Time $0 \mathrm{~h} 0 \mathrm{~min}$ : the start of incubation of a protoplast $(\mathrm{P})$ containing one nucleus with a dark nucleolus. The protoplast was released from the cell wall (w). Some of the dark bodies in the cytoplasm are probably mitochondria $(\mathrm{m})$. To the right of the protoplast there is a dying cell (c) with a cytoplasmic anucleate hernia (hl) penetrating through the digested wall.

(b) Time $1 \mathrm{~h} 12 \mathrm{~min}$. The regenerating wall is visible on the surface of the protoplast. Small vacuoles (v) are formed in the cytoplasm. The nucleus is in metaphase.

(c) Time 1 h $37 \mathrm{~min}$. Situation after nuclear division. Two daughter nuclei, with dark nucleoli, are apparent.

( $d$ Time $1 \mathrm{~h} 53 \mathrm{~min}$. Septum formation begins along a plane approximately perpendicular to the axis of the nuclear division. Centripetal growth of the septum from the plasma membrane is evident.

(e) Time $2 \mathrm{~h} 8 \mathrm{~min}$. The septum has closed during the preceding $15 \mathrm{~min}$. Further thickening of the septum starts centripetally, i.e. from the periphery of the protoplast. The septum has divided the original protoplast into two uninucleate halves: protoplasts I and II. Protoplast II continues to grow; protoplast I does not grow.

( $f$ ) Time $3 \mathrm{~h} 28 \mathrm{~min}$. In the growing protoplast II the dividing nucleus is visible. The septum has reached its final thickness.

(g) Time $4 \mathrm{~h} 4 \mathrm{~min}$. A second septum has formed, which divides protoplast II into protoplasts II and III. An anucleate hernia (h2) has originated from protoplast I, through its incomplete cell wall.

(h) Time $5 \mathrm{~h} 0 \mathrm{~min}$. Protoplast III grows; its nucleus is in prophase. The nucleolus is not clearly discernible. Inside the nucleus smaller dark spots are present. The second septum has reached its final thickness. Protoplast II has formed an anucleate hernia (h3) through its incomplete wall. The hernia probably remains in communication with the protoplast, because two further anucleate hernias (h4, h5) were later extruded by protoplast II (see $m$ ).

(i) Time $5 \mathrm{~h} 2 \mathrm{~min} 55 \mathrm{~s}$. The nucleus in protoplast III is in metaphase.

(j) Time $5 \mathrm{~h} 2 \mathrm{~min} 59 \mathrm{~s}$. The nucleus of the growing protoplast III is in anaphase.

(k) Time $5 \mathrm{~h} 3 \mathrm{~min} 3 \mathrm{~s}$. The nucleus of the growing protoplast III is in late anaphase.

(l) Time $5 \mathrm{~h} 57 \mathrm{~min}$. Daughter nuclei are well visible again in protoplast III. It continues to grow. Protoplasts I and II continue to regenerate a cell wall. Septum formation starts in protoplast III.

(m) Time $6 \mathrm{~h} 10 \mathrm{~min}$. An asymmetrically placed septum divides protoplast III into an anucleate protoplast (IV) and a binucleate protoplast (III). Anucleate hernias h4 and h5 have formed through the incomplete wall of protoplast II.

(n) Time 9 h 15 min. Protoplast I, having a complete cell wall, starts to revert to a cell. Protoplast II has died. Protoplast III, with one visible nucleus and an incomplete wall, stagnates. The anucleate protoplast IV vacuolizes; it is separated from III by a multilayered septum. Protoplast V (produced by growth of protoplast III and separated from it physically) has completed nuclear division: two nuclei are present. An asymmetrically placed septum starts to grow centripetally and divides protoplast $\mathrm{V}$ into $\mathrm{V}$ (binucleate) and VI (anucleate) compartments.

(o) Time $22 \mathrm{~h} 0 \mathrm{~min}$. Detail of regenerated protoplast I reverting to the cylindrical cell shape and reproducing by fission. An orientation mark for comparison with $a, d, g$ and $m$ is the original cell wall (w) of the yeast from which the protoplast was originally released. 
nuclei darker spherical or cap-like areas corresponding to nucleoli could be distinguished from the lighter nuclear mass (Fig. $1: a ; c ; g ; l ; m$ ). A few minutes before the onset of karyokinesis the sharp margins of the nucleoli disappeared.

Septation. The septum developed centripetally (Fig. $1: d-f ; m-n$ ). The time taken for closing of the septum ranged from 7 to $60 \mathrm{~min}$. Even after the septum had apparently been completed, communication between the two cell compartments went on for some time. The septum first formed as a thin primary layer (Fig. $1: d-e ; m$ ), which then gradually thickened (Fig. $1: d-f ; g-$ $h)$, up to $1.5 \mu \mathrm{m}$ in some cases, which is twice the normal septum thickness $(0.6-0.7 \mu \mathrm{m}$ in cells: unpublished data). The maximum thickness was usually attained by about $65 \mathrm{~min}$ after the beginning of septation. In some protoplasts multilayered septa were also formed (Fig. $1: m-n)$ between anucleate and binucleate compartments.

Relation of karyokinesis to septation. In some protoplasts the onset of karyokinesis was seen as early as $20 \mathrm{~min}$ after the beginning of incubation, in others as late as $150 \mathrm{~min}$. Karyokinesis was followed by septum formation in the plane approximately perpendicular to the axis of nuclear division (Fig. 1:d-g) about $33 \mathrm{~min}$ (range $\pm 10 \mathrm{~min}$ ) after division of the nucleus (in cells this lasted $23 \pm 5 \mathrm{~min}$ : unpublished data). This period was very similar in all 328 successive divisions studied, even though the length of the nuclear cycle (from karyokinesis to karyokinesis) ranged between 2.5 and $9 \mathrm{~h}$. The septum was produced earliest in primary binucleate protoplasts, i.e. those arising from cells that had accomplished karyokinesis but not septation before the protoplasts were prepared.

Relation of lateral wall regeneration and septation. Some of the protoplasts formed a thick cell wall over the whole surface after about $6 \mathrm{~h}$ (Fig. $1: \mathrm{m}, \mathrm{I}$ ) and later reverted to cells (Fig. $1: n, \mathrm{I} ; o$, I). The protoplasts which had only thin cell walls, both structurally and functionally incomplete, continued growing (Fig. $1: b-d ; e, \mathrm{II} ; f, \mathrm{II}: g, \mathrm{III} ; l, \mathrm{III} ; m, \mathrm{III} ; n, \mathrm{~V}, \mathrm{VI}$ ) in a multipolar or, more frequently, unipolar manner. Septation did not occur unless at least some cell wall regeneration had taken place. In primary binucleate protoplasts also, septation started after an incomplete wall was formed (after 1.5-3 h). The septum usually did not divide the protoplast into two equal halves (Fig. $1: e ; g ; m$ ). Due to the formation of only an incomplete wall, the daughter protoplasts were of various shapes and, due to asymmetric positioning of septa, of differing sizes. They continuously produced anucleate 'hernias' through the incomplete wall (Fig. $1: g, h 2 ; h$, $h 3 ; m, h 4, h 5)$. No relation was found between the differing thickness of the wall and the asymmetric position of the septum. Only the protoplasts that formed complete cell walls and reverted to cells survived. The others gradually died during the next few divisions.

Asymmetric formation of the septum (Fig. $1: m-n$ ) in growing protoplasts led to the production of both anucleate (Fig. $1: m, I V ; n$, IV, VI) and binucleate compartments (Fig. $1: m, I I I n$, V). The anucleate parts survived for several tens of hours, but did not form septa; they vacuolized (Fig. $1: m$, IV, h $3 ; n$, IV) and gradually died. The secondary binucleate protoplasts went on growing and forming an incomplete wall. Both nuclei later divided in a synchronous fashion and the cell cycle was repeated. Their further fate was not studied in detail.

\section{DISCUSSION}

Time-lapse microcinematographic recording of the cytological processes in $S$. japonicus var versatilis revealed valuable information on their dynamics. However, the number of cells that could be analysed was limited. Therefore only those findings that appeared frequently enough to allow some degree of generalization will be discussed.

In the first place the results reported here throw new light on the relationship of cytokinesis to cell wall regeneration associated with reversion of the protoplast to a cell. Previous studies on yeast protoplast regeneration have been based on the assumption that protoplast reversion to a cell can occur only after the cell wall has been completely regenerated (Nečas, 1971 ; Nečas \& Svoboda, 1981; Havelková, 1981). The analysis of behaviour of flattened protoplasts of $S$. japonicus var. versatilis showed that the incomplete wall on their surface, though incapable of 
initiating reversion to a cell, was nevertheless a 'morphogenetically active' structure because it could induce the formation of a septum. Although septation was not associated with a genetically determined shape (i.e. cylindrical cell) it carried out a biological function such as the separation of duplicated cytoplasm and genomes. The resultant daughter protoplasts could divide for a limited period. In this organism cytokinesis is evidently dissociated from the genetically determined renewal of cell shape.

As flattened protoplasts of $S$. japonicus var. versatilis do not have a complete rigid wall, they attain various shapes. In our preparations septa were frequently found in atypical positions. Because in protoplasts growing in a polar manner the septum often formed near the 'growing pole' where the wall was thin, it could be concluded that the place for septum initiation was not determined by the wall thickness (i.e. by the degree of wall organization). The septum generally formed perpendicular to the axis of the dividing nucleus, as suggested by Girbardt (1979), but there were many variations. The latter may be accounted for by flattening of protoplasts, which might alter the space orientation of cytoskeletal components and thus affect the direction of the signal, in which microtubules and microfilaments are possibly involved (Margolis \& Wilson, 1981).

Valuable data contributing to the elucidation of the control of cytokinesis have been gained through studies of the temperature-sensitive cell division cycle mutants of Schizosaccharomyces pombe in which mutations affect the septation process (Minet et al., 1979; Streiblová, 1981). On the basis of these studies it was suggested that the induction of septation depends on the position of the dividing nucleus (Streiblová \& Girbardt, 1979). In $S$. japonicus var. versatilis nuclei are clearly visible, so it was possible to study the relation between karyokinesis and septation in vivo. In all 328 cytokineses of flattened protoplasts having an incomplete wall, septation was always associated with the preceding karyokinesis. This relation was also demonstrated by the fact that the time between karyokinesis and the onset of septation was fairly constant ( $33 \pm 10 \mathrm{~min})$. It has been suggested (Girbardt, 1979; Minet et al., 1979) that during karyokinesis a signal is issued to initiate septation. The signal might be received by the plasma membrane, the cytoskeletal components or the cell wall. Primary binucleate protoplasts lack one of these possible targets: the original cell wall. Upon incubation the protoplasts started to form septa but only after they had synthesized new wall structures. This unambiguously shows that the primary target for the signal initiating septation in protoplasts is not the original cell wall of the yeast cell, but some other cell structure. This suggests that though not a primary target for the septum initiating signal, regardless of whether it is complete or not, the wall is a necessary prerequisite for the formation (anchoring) of a septum.

The course of nuclear division in flattened protoplasts of $S$. japonicus var. versatilis is similar to that described for $S$. pombe cells by McCully \& Robinow (1971). In some papers concerning multinuclear protoplasts (Nečas et al., 1961; Havelková \& Kř́palová, 1980) asynchronous karyokineses have been reported. In the binuclear protoplasts of $S$. japonicus var. versatilis nuclei always divided in a synchronous fashion (unpublished data). However, one may assume that with the increasing number of nuclei in the protoplast errors are occurring in the control of karyokineses, and are expressed as asynchrony.

The author expresses his thanks to Professor C. F. Robinow and Dr Eva Streiblová for kindly making a critical reading of the manuscript.

\section{REFERENCES}

GABRIEL, M. (1971). The study of formation, growth and regeneration of yeast protoplasts by means of time-lapse cinematography. Folia microbiologica 16, 500.

GABRIEL, M. (1984). Karyokinesis and cell septum formation during incomplete cell wall regeneration in flattened Schizosaccharomyces versatilis protoplasts. In Progress in Cell Cycle Controls. Proceedings of the 6th International Cell Cycle Workshop, pp. 144146. Edited by J. Chaloupka, A. Kotyk, \& E. Streiblová. Prague: Institute of Microbiology.

GABRIEL, M. \& KOPECKÁ, M. (1983). Regeneration of the cell wall of protoplasts of the fission yeast Schizosaccharomyces versatilis in liquid media and their reversion to cells. Folia microbiologica 28, 452-457.

GIRBARDT, M. (1979). A microfilamentous septal belt 
(FSB) during induction of cytokinesis in Tremetes versicolor (L. ex Fr.). Experimental Mycology 3, 215243.

Havelicoví, M. (1981). Multiple septaton in multinuclear protoplasts of Schizosaccharomyces pombe. Zeitschrift für allgemeine Mikrabiologie 21, 261266.

HavelKová, M. \& KŘ́palová, J. (1980). Karyokinesis in growing and reverting protoplasts of Schizosaccharomyces pambe. Folia micrabiologica 25, 219227.

Kopecki, M. (1975). The use of the antibiotic lomofungin for demonstration of nuclei and chromosomes in live yeast cells and protoplasts. Folia micro. biologica 21, 406-408.

KOPECK'́ M. \& GABRiel, M. (1978). Staining the nuclei in cells and protoplasts of living yeasts, moulds and green algae with the antibiotic lomofungin. Archives of Microbiology 119,305-311.

Margolis, R. L. \& WILSON, L. (1981). Microtubule treadmills - possible molecular machinery. Nature, London 293, 705-711.

McCully, E. K. Robnow, C. F. (1971). Mitosis in the fission yeast Schizosaccharomyces pambe: a comparative study with light and electron microscopy. Joumal of Cell Science 9, 475-507.

Minet, M., Nurse, P., Thuriax, P. \& Mitchison, J.M. (1979). Uncontrolled septation in a cell division cycle mutant of the fission yeast Schizosaccharomyces pombe. Journal of Bacteriology 137, 440-446.
Müller, R. (1956). Lebendnachweis des Zellkerns der Hefe im Phasenkontrastenmikroskop. Naturwissenschafien 43, 428-429.

Nečcas, O., Janisch, R., Jahoda, J. \& Gabrjel, $M$. (1961). Division of the nuclei of naked yeast protoplasts. Folia microbiologica 7, 202-205.

NEČAs, O. (1959). Nuclear structure of growing naked protoplasts of yeasts. Nature, London 184, 1664 1665 .

NećAs, O. (1961). Physical conditions as important factors for the regeneration of naked yeast protoplasts. Nature, London 192, 580.

NećAs, O. (1971). Cell wall synthesis in yeast protoplasts. Bacteriological Reviews 15, 149-170.

Nećas, O. Svoboda, A. (1981). Morphogenesis in protoplasts. In Yeast Cell Envelopes: Biachemistry. Biophysics and Ultrastructure, vol. 2, pp. 105-127. Edited by W. N. Arnold, Boca Raton: CRC Press. Robinow, C. F. (1975). Preparation of yeasts for light microscopy. Methods in Cell Biology 11, 1-22.

Streibloví, E. (1981). Fission. In Yeast Cell Enve. lopes: Biochemistry, Biophysics and Ultrastructure, vol. 2, pp. 79-92. Edited by W. N. Arnold. Boca Raton: CRC Press

Strejbloví, E. \& Girbardt, M. (1979). Microfilaments and cytoplasmic microtubules in cell division cycle mutants of Schizasaccharomyces pombe. Cana. dian Journal of Micrabiology 26, 250-254.

SVOBODA, A. (1966). Regeneration of yeast protoplasts in agar gels. Experimental Cell Research 44, 640-642. 